\title{
Clinical research in cancer palliative care: a metaresearch analysis
}

\section{Marie Vinches (D) , ${ }^{1,2}$ Anouk Neven, ${ }^{3}$ Laurène Fenwarth, ${ }^{1}$ Mitsumi Terada, ${ }^{4}$ Giovanna Rossi, ${ }^{1}$ Sarah Kelly, ${ }^{5,6}$ Julien Peron, ${ }^{7}$ Muriel Thomaso, ${ }^{8}$ Mogens Grønvold, ${ }^{9}$ Teresa De Rojas ${ }^{1}$}

- Additional material is published online only. To view please visit the journal online (http://dx.doi.org/10.1136/ bmjspcare-2019-002086).

${ }^{1}$ Medical Department, EORTC Headquarters, Brussels, Belgium ${ }^{2}$ Medical Oncology Department, Institut Régional du Cancer de Montpellier (ICM), Montpellier, France

${ }^{3}$ Statistics Department, EORTC Headquarters, Brussels, Belgium ${ }^{4}$ International Trials Management Section, Clinical Research Support Office, National Cancer Center Hospital, Chuo-ku, Japan ${ }^{5}$ Fellowship Program, SIOP Europe, Brussels, Belgium ${ }^{6}$ Data Management Department, EORTC Headquarters, Brussels, Belgium

${ }^{7}$ Medical Oncology Department, Cancer Institute of the "Hospices Civils" of Lyon, Lyon, France ${ }^{8}$ Supportive Care Department, Institut Régional du Cancer de Montpellier (ICM), Montpellier, France

${ }^{9}$ Department of Palliative Medicine, Bispebjerg Hospital, Copenhagen University Hospital, Kobenhavn, Denmark

\section{Correspondence to} Dr Marie Vinches, EORTC, Brussels 1200, Belgium; vinchesmarie@gmail.com

Received 23 October 2019 Revised 30 January 2020 Accepted 10 February 2020 Published Online First 24 March 2020

\section{Check for updates}

(C) Author(s) (or their employer(s)) 2020. No commercial re-use. See rights and permissions. Published by BMJ.

To cite: Vinches $M$, Neven $A$, Fenwarth $\mathrm{L}$, et al. BMJ Supportive \& Palliative Care 2020:10:249-258.

\section{ABSTRACT}

Objective This metaresearch of the clinicaltrials. gov database aims to evaluate how clinical research on palliative care is conducted within the setting of advanced cancer.

Methods Clinicaltrials.gov was searched to identify registered studies recruiting patients with cancer, and investigating issues relevant to palliative care. The European Organisation for Research and Treatment of Cancer QLQC15-PAL (Quality of Life in palliative cancer care patients) questionnaire was taken into account to define the research domains of interest. Studies investigating cancer-directed therapy, management of cancer treatmentrelated adverse events and diagnostic tests were excluded. Publication status was crosschecked using PubMed.

Results Of 3950 identified studies, 514 were included. The most frequent reason for exclusion was cancer-directed therapy (2491). In 20072012, 161 studies were registered versus 245 in 2013-2018. Included studies were interventional (84\%) or observational (16\%). Most studies were monocentric (60\%), sponsored by academia (79\%), and conducted in North America (57\%) or Europe (25\%). Seventy-nine per cent of studies evaluated a heterogeneous population (>1 tumour type). Interventional studies most frequently investigated systemic drugs (34\%), behavioural interventions (29\%) and procedures for pain (24\%). Pain, quality of life and physical function were the most frequently studied research domains $(188,95$ and 52 studies, respectively). The most applied primary outcome measures were efficacy/symptom control (61\%), quality of life (14\%) and feasibility (12\%). Only $16 \%$ of the closed studies had published results in PubMed.

\section{Conclusions Our study describes the} heterogeneous landscape of studies conducted to address the issues of patients with advanced cancer in palliative care. Albeit the observed increase in the number of studies over the last decade, the generalisation of the results brought by the existing trials is limited due to methodological issues and lack of reporting. A greater effort is needed to improve clinical research that supports evidence-based palliative cancer care.

\section{INTRODUCTION}

Palliative care, as defined by WHO, 'is an approach that improves the quality of life (QoL) of patients and their families facing the problems associated with lifethreatening illness, through the prevention and relief of suffering by means of early identification and impeccable assessment and treatment of pain and other problems, physical, psychosocial and spiritual'. According to WHO, over 19 million patients worldwide are in need of palliative care every year, and 34\% of them will die of cancer. ${ }^{2}$

Palliative care may be incorporated into patient management strategies at any stage of cancer, and integrated with tumourdirected treatment. ${ }^{3}$ There is growing evidence of the benefit of providing palliative care as early as possible in patients with advanced cancer, as it has the potential to improve survival, as well as QoL. ${ }^{45}$ In contrast, it has been shown that chemotherapy is deleterious when given during the last month of life. Many patients with cancer will reach a time where the best supportive care can be considered the best therapeutic option. ${ }^{67}$ All patients who die of cancer are in need of palliative care. ${ }^{8}$ Our study will focus within this setting on those patients which are no longer eligible to anticancer treatment.

Palliative care has evolved over time, and the oncology healthcare community has become increasingly aware of its importance. ${ }^{9} 10$ Nevertheless, the literature in the field suggests that there is limited evidence-based care for patients with cancer in palliative and end-oflife settings. ${ }^{11}{ }^{12}$ The holistic aim of 
palliative care makes it complex and challenging for clinical practice. It addresses multiple vital spheres of the patients and their families, including physical, emotional and social needs. Clinical research in this multifaceted setting brings several challenges. Historically, in the palliative care setting, slow recruitment and high attrition rates have made it difficult to carry out randomised controlled trials with sufficient sample size. ${ }^{13}$ The ethical considerations in this patient population, ${ }^{14}$ the lack of consensus and the multiplicity of available instruments to assess subjective outcomes (such as pain, fatigue or QoL), and the apparent insufficient research funding ${ }^{15}$ pose some further difficulties for conducting studies in this setting. ${ }^{16}$ Nevertheless, unmet needs remain and clinical research is still required to improve standards of care for patients with incurable cancer. ${ }^{17}$

This work analyses the current landscape of clinical research conducted in the palliative cancer setting, with the aim of better understanding the number and type of studies, study design and research topics. We present a meta-research study of the clinicaltrials.gov database with a quantitative and qualitative analysis of past and ongoing clinical trials and observational studies in patients with palliative cancer.

\section{MATERIAL AND METHODS}

We performed a metaresearch analysis: a meta-research is a study of research itself and aims to understand and evaluate research practices. ${ }^{18} 19$ The study methodology complies with the Preferred Reporting Items for Systematic Reviews and Meta-Analyses statement and guidelines, whenever applicable to the metaresearch context. ${ }^{20}$

\section{Study selection}

Clinicaltrials.gov database ${ }^{21}$ was searched to identify all studies registered before 1 January 2019, recruiting patients with cancer, and investigating issues relevant to palliative care. The decision on which issues to include was made by expert consensus, taking into account the European Organisation for Research and Treatment of Cancer QLQ-C15-PAL questionnaire. ${ }^{22}$ The selected issues/search terms were: "anxiety", "appetite", "cognitive function", "constipation", "depression", "dyspnoea", "emotional function", "fatigue", "nausea”, "pain", "palliative”, "quality of life”, "sleep disturbance" and "social function". Two searches per issue/search term were performed in January 2019 according to the following search algorithm: ["metastatic cancer" or "advanced cancer"] + [issue search term].

Eligible studies were interventional or observational, including patients with any type of malignancy in an advanced setting (metastatic, late-stage disease, life-limiting); and investigating supportive care, that is, any supportive intervention meant to improve patients' cancer-related symptoms, QoL, psychosocial and/or spiritual issues. Radiotherapy or invasive procedures when delivered to primarily address pain and studies investigating palliative symptom biomarkers or diagnostic tools were included as well. Studies investigating the following interventions were excluded: disease-directed therapies (eg, chemotherapies, immunotherapies, surgery or advanced therapies such as cell therapies); drugs or procedures to treat cancer treatment-related adverse events; diagnostic or theranostic procedures (eg, imaging modalities, biomarkers).

The study screening on clinicaltrials.gov was performed by one investigator (MV). Eligibility of all identified studies was assessed by at least two investigators (TDR, LF, MT, SK, GR, MV). Data extraction was performed by one investigator and subsequently reviewed by the principal investigator (MV) for all studies. In case of discrepancy, the decision was taken by consensus of the investigators. Further data cleaning and validation were carried out by AN.

\section{Data extraction}

Variables were partially extracted automatically from the clinicaltrials.gov database and were thereafter reviewed and manually encoded as needed through a standardised Microsoft Access 2016 file. Collected variables per study included baseline features (title, dates, location, sponsor), study design (type of study, design, randomisation, blinding, sample size), study population (age, life expectancy, disease), intervention(s), outcomes, palliative research domain, research field, use of patient-reported outcomes (PROs) and publication of results.

\section{Definition of variables}

The studies were divided in two main groups, interventional and observational, according to the definition of study type by clinicaltrials.gov.

Location of the study was defined as the continent where the study took place: North America, Europe, Asia, Other (ie, Oceania, South America, Africa), or intercontinental when the study was international including sites from more than one continent.

The number of centres was categorised as monocentric, multicentric national and multicentric international.

Study status was categorised as follows: ongoing (including recruiting, enrolling by invitation, active not recruiting, and suspended), closed (including terminated and completed), not yet recruiting, withdrawn or unknown status. Actual sample size was only considered for closed trials and planned sample size as reported on clinicaltrials.gov was considered for all the other included trials.

When an industrial party was mentioned among the sponsors, the study was considered sponsored by industry. Otherwise, the sponsor was considered academic. 


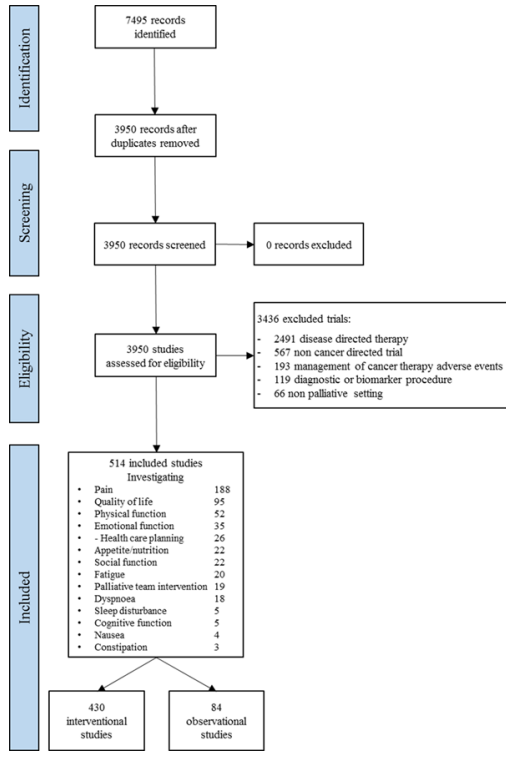

Figure 1 Preferred Reporting Items for Systematic Reviews and Meta-Analyses flow diagram.

Study design was defined as either single arm or multiarm for studies with two or more treatment groups or observational cohorts. We defined the study as blinded when any level of blinding (investigator, patient or reviewer) was reported.

The study population was categorised according to the selection criteria: any severe condition (ie, including patients with cancer and/or with other lifethreatening conditions), any malignancy, any haematological malignancy, any solid tumour, multiple tumour types (ie, when inclusion was restricted to a limited number of malignancies), or single tumour type.

The variable 'life expectancy' was defined as the minimum or maximum estimated life expectancy to enter the study, as indicated within the selection criteria.

The interventions were classified in the following categories: systemic drug, topic drug, nonconventional therapies (acupuncture, herbal medicine, etc), palliative team consultation, behavioural/social/ educational intervention (including physical activity), palliative diagnostic test/biomarker, procedure for pain or procedures for other symptoms. Procedure for pain included radiotherapy, high-intensity focused ultrasound (HIFU), MRI-guided HIFU (MR-HIFU), vertebral augmentation, radiofrequency, cryoablation, surgery, transcranial magnetic stimulation, photodynamic therapy, neurolysis and transelectrical nerve stimulation.

The symptom or issue faced by the patient that was addressed by the study was defined as a 'research domain' and categorised as follows: fatigue, dyspnoea, pain, sleep disturbance, appetite, nausea, constipation, emotional function (including anxiety, depression), global QoL, social function, cognitive function, physical function, healthcare planning and palliative care team performance.

The research domains were grouped into four research fields: biology (fatigue, dyspnoea, pain, sleep disturbance, appetite, nausea, constipation and physical function), psychology (emotional function, cognitive function, global QoL), sociology (social function) and ethics (healthcare planning, palliative care team performance).

Primary outcomes defined by the investigators and listed on clinicaltrials.gov were categorised as follows: efficacy (eg, symptom management, technique effectiveness), feasibility (including acceptability), global QoL, survival, quality of care (including care planning), epidemiology and biomarker evaluation. In studies with more than one primary outcome, all were collected.

When at least one of the primary outcome assessments was based on a PRO measure, the study was considered as 'using PROs'. The availability of published results according to clinicaltrials.gov was crosschecked with PubMed. ${ }^{23}$

Evolution over time of the number of studies was restricted to the period after 2007 to avoid bias, as the clinicaltrials.gov registration requirements were expanded after the FDA Amendments Act of 2007 (FDAAA) passed. ${ }^{24}$ The two 5-year periods, 2007-2012 and 2013-2018, were compared.

\section{Statistical analysis}

Median and IQR were used to describe quantitative data. Percentages were used to describe qualitative data. Percentages may not always total $100 \%$ due to rounding error.

The SAS software V.9.4 (SAS) was used to perform the analysis and to plot the results.

\section{RESULTS}

The clinicaltrials.gov database search resulted in 3950 studies; 514 (13\%) were included (figure 1). The most frequent reason for exclusion was cancerdirected therapy (2491), followed by studies not including patients with cancer (567). Included studies were predominantly interventional $(84 \%, 430 / 514)$ compared with observational studies $(16 \%, 84 / 514)$. Between 2007 and 2012, 161 studies were registered versus 245 over the period 2013-2018 (online supplementary figure 1 ).

\section{Study characteristics}

The main characteristics of the 514 included studies are shown in tables 1 and 2. Regarding the status of the studies, 32\% (162) were ongoing, 54\% (276) were closed and 15\% (76) were either withdrawn, not yet recruiting or with unknown status. The study status was similar between interventional and observational studies. Among the 276 closed studies, 18\% (51) had results available on clinicaltrials.gov and $16 \%(45)$ had results published in PubMed. Out of the 45 studies 
Table 1 Main study characteristics: operational, dissemination and design information

\begin{tabular}{|c|c|c|c|}
\hline & Interventional & Observational & Overall \\
\hline Number of studies & 430 & 84 & 514 \\
\hline \multicolumn{4}{|l|}{ Operational } \\
\hline \multicolumn{4}{|l|}{ Status } \\
\hline Ongoing & $134(31 \%)$ & $28(33 \%)$ & $162(32 \%)$ \\
\hline Closed & $227(53 \%)$ & $49(58 \%)$ & $276(54 \%)$ \\
\hline Not yet recruiting & $21(5 \%)$ & $2(2 \%)$ & $23(5 \%)$ \\
\hline Withdrawn & $11(3 \%)$ & $1(1 \%)$ & $12(2 \%)$ \\
\hline Unknown status & $37(9 \%)$ & $4(5 \%)$ & $41(8 \%)$ \\
\hline \multicolumn{4}{|l|}{ Sponsor } \\
\hline Academic & $339(79 \%)$ & $69(82 \%)$ & $408(79 \%)$ \\
\hline Industry & $91(21 \%)$ & $15(18 \%)$ & $106(21 \%)$ \\
\hline \multicolumn{4}{|l|}{ Location } \\
\hline North America & $248(58 \%)$ & $44(53 \%)$ & $292(57 \%)$ \\
\hline Europe & $97(23 \%)$ & $29(35 \%)$ & $126(25 \%)$ \\
\hline Asia & $46(11 \%)$ & $6(7 \%)$ & $52(10 \%)$ \\
\hline Intercontinental & $20(5 \%)$ & $4(5 \%)$ & $24(5 \%)$ \\
\hline Other & $14(3 \%)$ & $1(1 \%)$ & $15(3 \%)$ \\
\hline Unknown & $5(1 \%)$ & - & $5(1 \%)$ \\
\hline \multicolumn{4}{|l|}{ Number of centres } \\
\hline Monocentric & $257(60 \%)$ & $49(58 \%)$ & $306(60 \%)$ \\
\hline Multicentric national & $119(28 \%)$ & $21(25 \%)$ & $140(27 \%)$ \\
\hline $\begin{array}{l}\text { Multicentric } \\
\text { international }\end{array}$ & $24(6 \%)$ & $9(11 \%)$ & $33(6 \%)$ \\
\hline Unknown & $30(7 \%)$ & $5(6 \%)$ & $35(7 \%)$ \\
\hline \multicolumn{4}{|l|}{ Dissemination } \\
\hline \multicolumn{4}{|l|}{$\begin{array}{l}\text { Published results among } \\
\text { closed studies* }(n=276)\end{array}$} \\
\hline $\begin{array}{l}\text { Has results on } \\
\text { clinicaltrials.gov }\end{array}$ & $49(22 \%)$ & $2(4 \%)$ & $51(18 \%)$ \\
\hline $\begin{array}{l}\text { Publication on } \\
\text { PubMed }\end{array}$ & $40(18 \%)$ & $5(10 \%)$ & $45(16 \%)$ \\
\hline \multicolumn{4}{|l|}{ Design } \\
\hline \multicolumn{4}{|l|}{ Blinded } \\
\hline No & $286(67 \%)$ & - & $286(56 \%)$ \\
\hline Yes & $144(33 \%)$ & - & $144(28 \%)$ \\
\hline Not applicable & - & $84(100 \%)$ & $84(16 \%)$ \\
\hline \multicolumn{4}{|l|}{ Study arms } \\
\hline Single arm & $136(32 \%)$ & $67(80 \%)$ & $203(39 \%)$ \\
\hline Multiarm & $294(68 \%)$ & $17(20 \%)$ & $311(61 \%)$ \\
\hline \multicolumn{4}{|l|}{ Randomisation } \\
\hline No & $152(35 \%)$ & - & $152(30 \%)$ \\
\hline Yes & $278(65 \%)$ & - & $278(54 \%)$ \\
\hline Not applicable & - & $84(100 \%)$ & $84(16 \%)$ \\
\hline \multicolumn{4}{|l|}{$\begin{array}{l}\text { Number of primary } \\
\text { outcomes }\end{array}$} \\
\hline 1 & $337(78 \%)$ & $65(77 \%)$ & $402(78 \%)$ \\
\hline 2 & $38(9 \%)$ & $5(6 \%)$ & $43(8 \%)$ \\
\hline$\geq 3$ & $42(10 \%)$ & $8(10 \%)$ & $50(10 \%)$ \\
\hline Unknown & $13(3 \%)$ & $6(7 \%)$ & $19(4 \%)$ \\
\hline \multicolumn{4}{|l|}{$\begin{array}{l}\text { Actual sample size } \\
\text { among closed studies } \\
(n=276)\end{array}$} \\
\hline Median & 60 & 74 & 60 \\
\hline IQR & $21-150$ & $38-255$ & $23-177$ \\
\hline
\end{tabular}

\section{Table 1 Continued}

\begin{tabular}{llll}
\hline & Interventional & Observational & Overall \\
\hline \multicolumn{1}{c}{$\begin{array}{l}\text { Number of studies } \\
\text { Planned sample size } \\
\text { among non-closed } \\
\text { studies ( } n=238)\end{array}$} & 221 & 49 & 270 \\
\hline $\begin{array}{l}\text { Median } \\
\text { IQR }\end{array}$ & 72 & 230 & \\
\hline Number of studies & 202 & $50-500$ & 80 \\
\hline
\end{tabular}

*On clinicaltrials.gov, all trials with results were closed trials; nevertheless, we found additional publications on PubMed for 15 interventional not closed studies (seven ongoing trials, one not yet recruiting, two withdrawn and five unknown status)

with results published in PubMed, 15 were opened before 2007 and 24 were opened between 2007 and 2012. Most studies were sponsored by academia (79\%, $408)$, and conducted in North America $(57 \%, 292)$ or Europe $(25 \%, 126)$. Sixty per cent $(306)$ of the studies were monocentric and only $6 \%$ (33) were international multicentric studies. Among the interventional studies, $33 \%(144 / 430)$ were performed with blinding, and $65 \%(278 / 430)$ were randomised. Regarding closed studies $(n=276)$, the median actual sample size was 60 patients (IQR 21-150) for interventional studies and 74 (IQR 38-255) for observational studies. The median duration of the studies was 3 years (IQR 2-4 years). Regarding the non-closed studies $(n=238)$, the median planned sample size was 80 (IQR 38-200) overall. There were no apparent differences between the main characteristics of the observational and interventional studies, with the exception of the number of arms, where there was a majority of single arm designs $(80 \%, 67 / 84)$ among the observational studies but a majority of multiarm trials $(68 \%, 294 / 430)$ among the interventional studies. Complete data for the primary endpoint (palliative research domain) and most variables were available for all studies; unknown data were found for the variables 'status', 'number of centres', 'location' and 'number of primary outcomes', in less than $8 \%$ of the studies.

\section{Population}

The studied population is shown in figure 2. Seventynine per cent of studies evaluated a heterogeneous population, including more than one tumour type: patients with any malignancy were included in 250 studies (49\%); 80 studies (16\%) included patients with any solid tumour; 60 studies (12\%) included patients with multiple tumour types, and 14 studies (3\%) included patients with any severe condition (ie, including non-malignant diseases) and one study $(0.2 \%)$ was restricted to patients with only haematological malignancies. A hundred and nine studies (21\%) were tumour specific. Of these 109 studies, $39 \%$ (42) included only breast, $26 \%$ (28) lung cancer, $15 \%$ (16) prostate and 3\% (3) colorectal. The study 


\begin{tabular}{|c|c|c|c|}
\hline & Interventional & Observational & Overall \\
\hline \multicolumn{4}{|l|}{ Study population } \\
\hline \multicolumn{4}{|l|}{ Condition } \\
\hline Any severe condition & $9(2 \%)$ & $5(6 \%)$ & $14(3 \%)$ \\
\hline Any malignancy & $206(48 \%)$ & $44(52 \%)$ & $250(49 \%)$ \\
\hline $\begin{array}{l}\text { Any haematological } \\
\text { malignancy }\end{array}$ & $1(0 \%)$ & - & $1(0 \%)$ \\
\hline Any solid tumour & $71(17 \%)$ & $9(11 \%)$ & $80(16 \%)$ \\
\hline $\begin{array}{l}\text { Multiple tumour types } \\
\text { (restricted) }\end{array}$ & $50(12 \%)$ & $10(12 \%)$ & $60(12 \%)$ \\
\hline Single tumour type & $93(22 \%)$ & $16(19 \%)$ & $109(21 \%)$ \\
\hline $\begin{array}{l}\text { Restricted to patients } \\
\text { with bone metastases }\end{array}$ & $145(34 \%)$ & $21(25 \%)$ & $166(32 \%)$ \\
\hline \multicolumn{4}{|l|}{ Age } \\
\hline \multicolumn{4}{|l|}{ Minimum age } \\
\hline$\leq 17$ years & $31(7 \%)$ & $11(13 \%)$ & $42(8 \%)$ \\
\hline 18 years & $348(81 \%)$ & $65(77 \%)$ & $413(80 \%)$ \\
\hline 19-64years & $48(11 \%)$ & $7(8 \%)$ & $55(11 \%)$ \\
\hline$\geq 65$ years & $3(1 \%)$ & $1(1 \%)$ & $4(1 \%)$ \\
\hline \multicolumn{4}{|l|}{ Maximum age } \\
\hline$\leq 17$ years & $5(1 \%)$ & - & $5(1 \%)$ \\
\hline 18-64years & $7(2 \%)$ & $2(2 \%)$ & $9(2 \%)$ \\
\hline $65-120$ years & $65(15 \%)$ & $9(11 \%)$ & $74(14 \%)$ \\
\hline No upper limit & $353(82 \%)$ & $73(87 \%)$ & $426(83 \%)$ \\
\hline \multicolumn{4}{|l|}{ Life expectancy } \\
\hline \multicolumn{4}{|l|}{$\begin{array}{l}\text { Minimum life } \\
\text { expectancy }\end{array}$} \\
\hline $\begin{array}{l}>1 \text { week to } \\
<1 \text { month }\end{array}$ & $7(2 \%)$ & $4(5 \%)$ & $11(2 \%)$ \\
\hline$\geq 1$ to $<3$ months & $33(8 \%)$ & $4(5 \%)$ & $37(7 \%)$ \\
\hline$\geq 3$ to $<6$ months & $65(15 \%)$ & $9(11 \%)$ & $74(14 \%)$ \\
\hline $\begin{array}{l}\geq 6 \text { months to } \\
<1 \text { year }\end{array}$ & $31(7 \%)$ & $2(2 \%)$ & $33(6 \%)$ \\
\hline$\geq 1$ year & $9(2 \%)$ & $1(1 \%)$ & $10(2 \%)$ \\
\hline Not specified & 285 (66\%) & $64(76 \%)$ & $349(68 \%)$ \\
\hline \multicolumn{4}{|l|}{$\begin{array}{l}\text { Maximum life } \\
\text { expectancy }\end{array}$} \\
\hline$\leq 6$ months & $5(1 \%)$ & $3(4 \%)$ & $8(2 \%)$ \\
\hline $\begin{array}{l}>6 \text { months to } \\
\leq 1 \text { year }\end{array}$ & $10(2 \%)$ & $4(5 \%)$ & $14(3 \%)$ \\
\hline$\leq 2$ years & $2(0 \%)$ & - & $2(0 \%)$ \\
\hline Not specified & $413(96 \%)$ & 77 (92\%) & $490(95 \%)$ \\
\hline \multicolumn{4}{|l|}{ Study aim } \\
\hline \multicolumn{4}{|l|}{ Intervention } \\
\hline Systemic drug & 148 (34\%) & - & $148(29 \%)$ \\
\hline $\begin{array}{l}\text { Behavioural } \\
\text { intervention }\end{array}$ & $125(29 \%)$ & - & $125(24 \%)$ \\
\hline Physical activity & 20 & & 20 \\
\hline Procedure for pain & $103(24 \%)$ & - & $103(20 \%)$ \\
\hline Radiotherapy & 48 & & 48 \\
\hline MR-HIFU & 16 & & 16 \\
\hline $\begin{array}{l}\text { Vertebral } \\
\text { augmentation }\end{array}$ & 12 & & 12 \\
\hline Radiofrequency & 8 & & 8 \\
\hline Cryoablation & 7 & & 7 \\
\hline Surgery & 4 & & 4 \\
\hline Other & 8 & & 8 \\
\hline
\end{tabular}

Continued
Table 2 Continued

\begin{tabular}{|c|c|c|c|}
\hline & Interventional & Observational & Overall \\
\hline $\begin{array}{l}\text { Palliative team } \\
\text { consultation }\end{array}$ & $24(6 \%)$ & - & $24(5 \%)$ \\
\hline $\begin{array}{l}\text { Nonconventional } \\
\text { therapies }\end{array}$ & $16(4 \%)$ & - & $16(3 \%)$ \\
\hline $\begin{array}{l}\text { Procedure for other } \\
\text { symptom }\end{array}$ & $9(2 \%)$ & - & $9(2 \%)$ \\
\hline $\begin{array}{l}\text { Palliative diagnosticl } \\
\text { biomarker }\end{array}$ & $4(1 \%)$ & - & $4(1 \%)$ \\
\hline Topic drug & $1(0 \%)$ & - & $1(0 \%)$ \\
\hline Not applicable & - & $84(100 \%)$ & $84(16 \%)$ \\
\hline \multicolumn{4}{|l|}{ Research domain studied } \\
\hline Pain & $170(40 \%)$ & $18(21 \%)$ & $188(37 \%)$ \\
\hline Quality of life (global) & $77(18 \%)$ & $18(21 \%)$ & $95(19 \%)$ \\
\hline Physical function & $45(10 \%)$ & $7(8 \%)$ & $52(10 \%)$ \\
\hline Emotional function & $31(7 \%)$ & $4(5 \%)$ & $35(7 \%)$ \\
\hline Healthcare planning & $11(3 \%)$ & $15(18 \%)$ & $26(5 \%)$ \\
\hline Appetite/nutrition & $20(5 \%)$ & $2(2 \%)$ & $22(4 \%)$ \\
\hline Social function & $17(4 \%)$ & $5(6 \%)$ & $22(4 \%)$ \\
\hline Fatigue & $17(4 \%)$ & $3(4 \%)$ & $20(4 \%)$ \\
\hline $\begin{array}{l}\text { Palliative team } \\
\text { performance }\end{array}$ & $14(3 \%)$ & $5(6 \%)$ & $19(4 \%)$ \\
\hline Dyspnoea & $17(4 \%)$ & $1(1 \%)$ & $18(4 \%)$ \\
\hline Cognitive function & $5(1 \%)$ & - & $5(1 \%)$ \\
\hline Sleep disturbance & $2(0 \%)$ & $3(4 \%)$ & $5(1 \%)$ \\
\hline Nausea & $3(1 \%)$ & $1(1 \%)$ & $4(1 \%)$ \\
\hline Constipation & $1(0 \%)$ & $2(2 \%)$ & $3(1 \%)$ \\
\hline \multicolumn{4}{|l|}{ Research field } \\
\hline Biology & $275(64 \%)$ & $37(44 \%)$ & $312(61 \%)$ \\
\hline Psychology & $113(26 \%)$ & $22(26 \%)$ & $135(26 \%)$ \\
\hline Sociology & $17(4 \%)$ & $5(6 \%)$ & $22(4 \%)$ \\
\hline Ethics & $25(6 \%)$ & $20(24 \%)$ & $45(9 \%)$ \\
\hline \multicolumn{4}{|l|}{ Primary outcome* } \\
\hline $\begin{array}{l}\text { Efficacy/symptom } \\
\text { control }\end{array}$ & $277(64 \%)$ & $39(47 \%)$ & $316(61 \%)$ \\
\hline Quality of life & $60(14 \%)$ & $13(16 \%)$ & $73(14 \%)$ \\
\hline $\begin{array}{l}\text { Feasibility/ } \\
\text { acceptability }\end{array}$ & $55(13 \%)$ & $5(6 \%)$ & $60(12 \%)$ \\
\hline Quality of care & $25(6 \%)$ & $15(18 \%)$ & $40(8 \%)$ \\
\hline Safety & $31(7 \%)$ & $2(2 \%)$ & $33(6 \%)$ \\
\hline Biomarker & $10(2 \%)$ & $6(7 \%)$ & $16(3 \%)$ \\
\hline Survival & $5(1 \%)$ & $1(1 \%)$ & $6(1 \%)$ \\
\hline Epidemiology & - & $4(5 \%)$ & $4(1 \%)$ \\
\hline
\end{tabular}

Evaluation of outcome

with PROs

\begin{tabular}{llll} 
Yes & $262(61 \%)$ & $35(42 \%)$ & $297(58 \%)$ \\
No & $155(36 \%)$ & $43(51 \%)$ & $198(9 \%)$ \\
NA & $13(3 \%)$ & $6(7 \%)$ & $19(4 \%)$ \\
\hline
\end{tabular}

*Studies could have more than one primary outcome (see table 1 'Number of outcomes') therefor percentages do not sum up to $100 \%$.

MR-HIFU, MRI-guided high-intensity focused ultrasound; NA, not applicable; PRO, patient-reported outcome.

population was restricted to patients with bone metastasis in 32\% (166) of the studies.

The lower age limit for inclusion was 18 years of age for $80 \%$ (413) of the studies. The majority of studies 


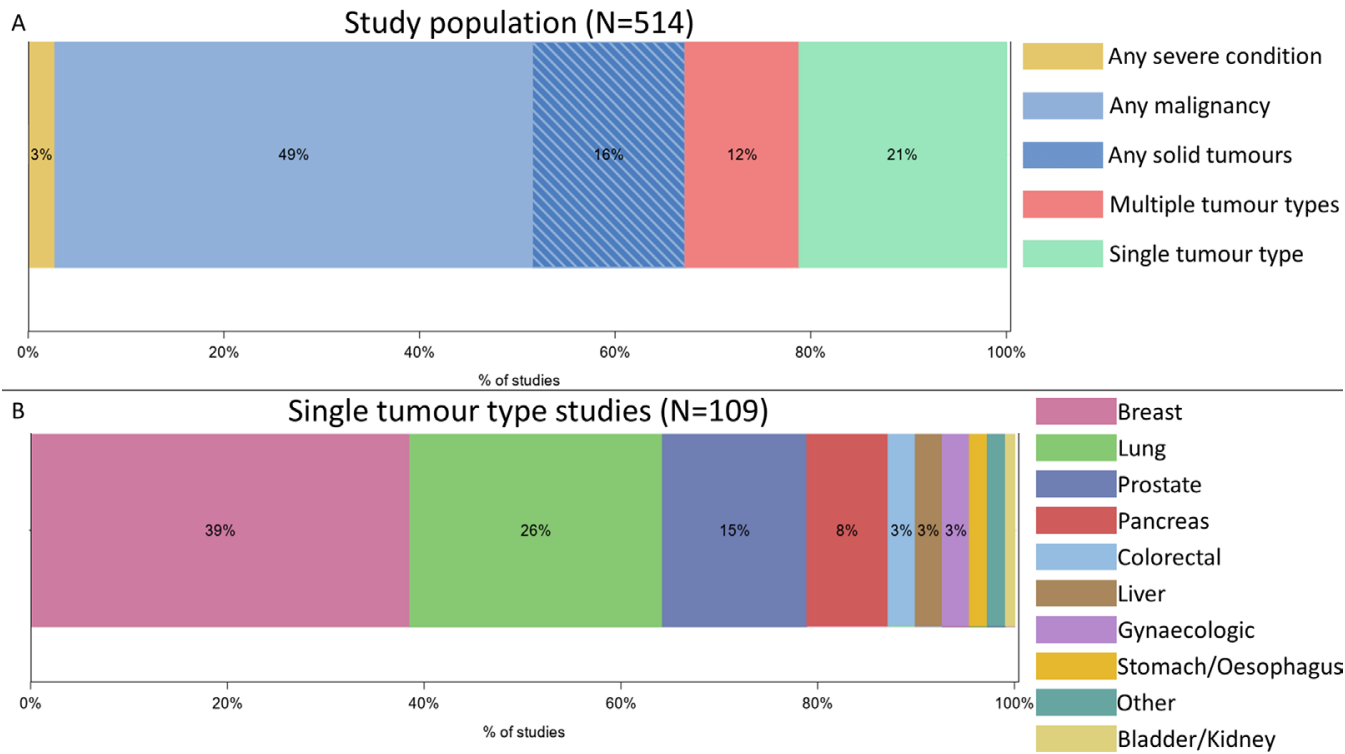

Figure 2 Study population. (A) Eligible conditions for all studies. (B) Eligible cancer type for studies that only investigated one type of tumour.

did not define an upper age limit $(83 \%, 426)$. Only five (1\%) studies focused on the paediatric population (age $<18$ years), and four (1\%) on the elderly population (age $\geq 65$ years).

Life expectancy estimation was a defined selection criterion for 35\% (180) of the studies. The majority of these studies $(92 \%, 165 / 180)$ required a minimum life expectancy ranging from 1 week to 1 year. A maximum life expectancy was required in only 13\% (24/180) of the studies, with the threshold being above 6 months in 16 studies.

\section{Intervention}

Interventional studies most frequently investigated systemic drugs $(34 \%, 148 / 430)$ or behavioural interventions $(29 \%, 125 / 430)$. Systemic drugs investigated included bisphosphonates, antiemetics, pain medication and others. Physical activity was investigated in $16 \%$ $(20 / 125)$ of the behavioural intervention studies. Other

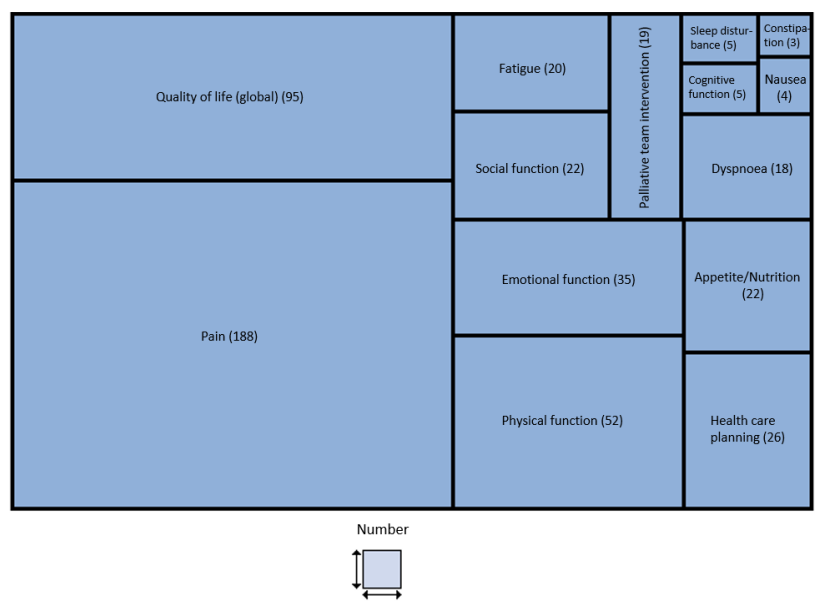

Figure 3 Number of trials per palliative research domain. behavioural interventions included educational interventions, communication and coping programme. Procedures for pain were investigated in $24 \%$ of the trials (103/430), using radiotherapy in $47 \%$ of them (48/103), MR-HIFU in 16\% (16), vertebral augmentation in $12 \%$ (12) or other procedures for pain in 26\% (27).

Other interventions included palliative team consultation $(6 \%, 24 / 430)$, non-conventional therapies $(4 \%$, 16/430), procedures targeting other symptoms besides pain $(2 \%, 9 / 430)$ and palliative biomarkers $(1 \%, 4 / 430)$.

\section{Research domain and research field}

Pain was the palliative research domain (ie, issue faced by the patient) investigated in the largest proportion of studies (37\%, 188/514), followed by QoL and physical function (19\% 95/514 and 10\% 52/514 studies, respectively; figure 3). Fatigue, appetite and dyspnoea each represented only $4 \%$ of the studies. Observational studies investigated pain less often (21\% vs $40 \%)$, and healthcare planning more often ( $18 \%$ vs $3 \%)$ than interventional trials.

The most studied research field was biology $(61 \%$ of studies, 312/514), followed by psychology (26\%, $135 / 514)$. Observational studies investigated ethics more often ( $24 \%$ vs $6 \%$ ), and biology less often (44\% vs $64 \%$ ) than interventional trials.

\section{Outcome}

One single primary outcome (ie, criteria defined by the investigator) was specified for 402 (78\%) studies, 43 (8\%) studies had 2 primary outcomes and 50 (10\%) studies had 3 or more defined primary outcomes.

The most frequently applied primary outcomes were efficacy of the intervention or symptom control (61\%, $316 / 514)$, QoL $(14 \%, 73)$ and feasibility $(12 \%, 60)$. Other primary outcomes were quality of care or care 


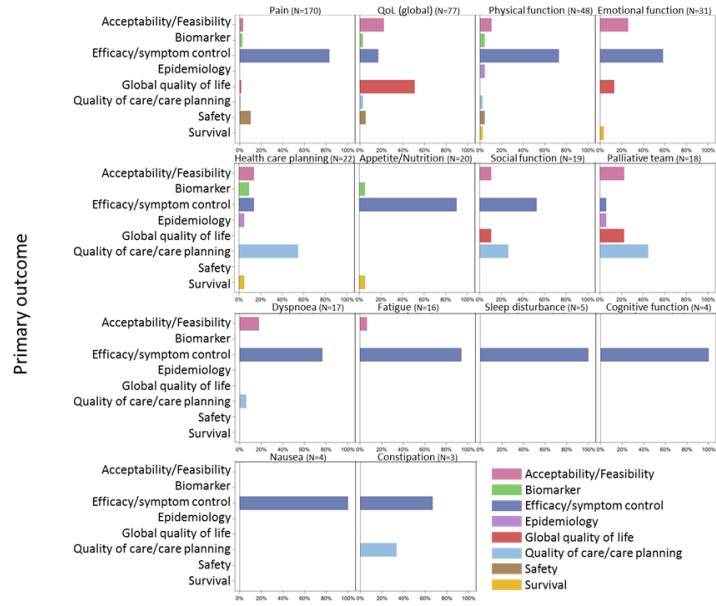

Figure 4 Primary outcome used per palliative research domain, reported in percentages. Only studies with one primary outcome and studies with several primary outcomes belonging to the same category are displayed $(n=454 ; 88 \%)$. QoL, quality of life.

planning $(8 \%, 40)$, safety $(6 \%, 33)$, biomarker $(3 \%$, $16)$, survival $(1 \%, 6)$ and epidemiology $(1 \%, 4)$. There were differences in the primary outcome between interventional and observational studies: efficacy/ symptom control was applied in $64 \%$ versus $47 \%$, quality of care in $6 \%$ versus $18 \%$ and feasibility in $13 \%$ versus $6 \%$, respectively.

For the majority of research domains (11/14), efficacy/ symptom control was the most investigated outcome (figure 4). For three research domains, other outcomes were more frequently used: for the studies investigating global QoL issues, QoL outcomes were predominantly applied; for healthcare planning and palliative care team performance domains, the most used outcome was quality of care/care planning.

PROs were used for the assessment of primary outcomes in $61 \%$ of the interventional trials and in $42 \%$ of the observational studies.

\section{DISCUSSION}

Our study describes the heterogeneous landscape of studies conducted to address the issues of patients with advanced cancer in palliative care. The observed quantity and quality of the studies suggest that greater efforts are needed to improve clinical research that supports evidence-based palliative cancer care.

When searching for [Cancer] on clinicaltrials.gov, over 69000 studies can be found (69 600 studies on 12 August 2019). Out of those, only 514 studies $(0.8 \%)$ were identified in our metaresearch work as studies aiming to investigate palliative care for patients with advanced cancer. A proportionally small number of palliative care studies is conducted when compared with the total number of cancer research studies. We observed an increase in the number of studies over the last years (from 161 studies in 2007-2012 to 245 studies in 2013-2018), which constitutes a positive sign of paradigm shift. Yet, even if palliative care awareness has progressed in the last decades, a great effort is still needed to improve the life of patients with advanced cancer. ${ }^{25}$

Over 9.5 million patients died of cancer worldwide in $2018 .{ }^{26}$ However, in an ever-growing cancer research landscape, it is appalling to observe the low proportion of research dedicated to this patient population. Beyond the apparent quantitative deficit of cancer palliative research as observed in clinicaltrials.gov, our study shows qualitative shortfalls. In the era of personalised medicine, the 'one size fits all' approach is becoming obsolete. Personalised medicine can be considered in alignment with the scope of palliative care, as it falls within the scope of WHO concept of Universal Health Coverage (UHC): 'UHC means that all individuals and communities receive the health services they need without suffering financial hardship. It includes the full spectrum of essential, quality health services, from health promotion to prevention, treatment, rehabilitation, and palliative care'. ${ }^{27}$ Nevertheless, in the field of palliative care, patient management algorithms often do not rely on individualised medicine, but are rather symptom driven and cross tumoural. Consequently, trials investigating palliative care frequently include a very heterogeneous patient sample (49\% of studies included patients with any malignancy). This approach may leave specific needs of particular patient populations unmet. Indeed, the physiopathology of symptoms may differ between different clinical settings, which should be taken into account to deliver the best treatment to patients. In addition to these biological factors, and again in alignment with WHO definition of UHC, broader determinants of health (including social, economic, environmental, as well as people's characteristics and behaviours) should be considered and incorporated into future palliative care research. ${ }^{2728}$

Another qualitative concern arises from the majority of studies identified in clinicaltrials.gov being monocentric $(60 \%)$ and with a limited sample size (median of 60 patients), which can have an impact on the power to detect differences between treatment strategies and on the generalisability of results. However, the methodology of the trials appears to be reliable, with a large proportion of the investigational trials using randomisation (65\%) and blinding (34\%) to minimise bias. These findings are to put in line with the fact that when considering palliative oncology literature, the majority of published studies consist of case report studies, with a lower level of evidence. ${ }^{29} 30$

Another relevant finding of our study is the unbalance across the studied research domains. Patients with incurable cancer bear a high symptom burden as they approach death ${ }^{31}$ : fatigue, pain, lack of energy, weakness and appetite loss are the most frequent symptoms, occurring in more than half of patients. ${ }^{32}$ According to Seow et al, pain, nausea, anxiety and 
depression scores remain relatively stable over the last 6 months of life. ${ }^{31}$ Nonetheless, shortness of breath, drowsiness, lack of appetite and tiredness increase in severity over time, particularly in the month before death. According to our study, pain is the research domain most often investigated (37\%), but only $4 \%$ of the studies focus on the management of fatigue, and a further $4 \%$ on the management of appetite loss and nutritional problems-despite fatigue, pain and appetite loss being the most frequent symptoms in this patient population. Another alarming finding is that dyspnoea, one of symptoms that worsens at the end of life and is particularly devastating for the patient and caregivers, was only investigated in a small number of studies according to clinicaltrials.gov $(n=18,4 \%) .{ }^{313}$ We acknowledge that the number of clinical trials may not accurately represent how extensively a research topic is studied. Furthermore, the relative scarcity of research in a certain domain could be illustrating the actual challenge in conducting studies in that area. This is particularly true in palliative care research, and it adds to the challenge of including severely ill patients in clinical trials, and to the existing high attrition rates. ${ }^{34}$ Our study suggests that unmet needs remain, regarding the identification and the management of the burdensome symptoms associated with cancer progression and the last months of life. Further research is needed to answer the questions on how best to treat these symptoms. Additionally, the most studied research field was biology. While most oncology research studies are biology centred, a more holistic approach might be particularly desirable for palliative care research, expanding the research interests to the fields of psychology, sociology and ethics. ${ }^{35} 36$

As defined by WHO, palliative care aims to improve the QoL of the patients facing life-threatening illness by means of a multidisciplinary approach. ${ }^{1}$ Our study identified efficacy/symptom control as the most used primary outcome (61\%), while QoL per se was less frequently used as a primary endpoint (14\%). However, symptom control is correlated to health-related QoL and may be considered as a surrogate measure of QoL in the palliative setting. ${ }^{37}$ Furthermore, more than 50\% of the studies identified in clinicaltrials.gov used PROs to measure the primary outcome. These encouraging findings align with the current multistakeholder push to promote patient-centred research. ${ }^{38}{ }^{39}$ In fact, the field of QoL has been exponentially expanding since the 1980 s. $^{40}$ QoL is not to be understood as a single health index, but as the essence of palliative care, considering the patient's well-being as a whole. ${ }^{41} 42$

It is worrisome that despite the limited number of palliative care research studies in clinicaltrials.gov, the results seem to be insufficiently shared with the scientific community. Among the closed studies included in our work, only $16 \%$ had results available on PubMed and $18 \%$ on clinicaltrials.gov. While this is not a problem unique to the palliative care setting with an estimated general publication rate of $46 \%$ in medical research, the proportion of published results in palliative care research seems particularly low. ${ }^{43} 44$.

The limitations of our work need to be acknowledged. The study search was limited to clinicaltrials.govonly, and restricted within certain research domains. This database is being more and more used to evaluate research practices; however, understanding the limitations of the database is crucial to perform a valid analysis. ${ }^{45}$ While clinicaltrials.gov is the largest publicly available database, we may have underestimated the number of studies as some may not be registered, especially observational studies, which can be of particular relevance in the palliative care field. Furthermore, we have to acknowledge the dynamic nature of clinicaltrials.gov, as the incentives for reporting trials have changed over time. Including two key policy changes for clinical trial reporting on clinicaltrials.gov: the 2005 requirement by the International Committee of Medical Journal Editors to register all clinical trials as a condition for publication of results ${ }^{46}$ and the 2007 requirement by the FDAAA to register non-phase 1 clinical trials of drug and biological products, as well as non-feasibility trials of device products. ${ }^{24}$ An other limiting aspect includes the possible under-representation of trials conducted out of Western countries and the lack of data regarding the ability of specific groups of patients to participate in trials. ${ }^{47}$ In spite of these shortfalls, clinicaltrials.gov remains the largest publicly available trial database, and we believe it to be better suited for the proposed research question, as it takes most registered trials into account. Moreover, a search based on published results (eg, a PubMed search) would only have yielded 60 studies $(11.7 \%, 60 / 514)$ of those that we were able to identify at clinicaltrials.gov, and hence would have substantially limited the scope of our research question.

While the investment in palliative care has increased over time, a limited number of studies have been conducted to address the issues of patients with advanced cancer who are not receiving active oncological treatment. Furthermore, the generalisation of the results brought by the existing trials is limited due to methodological issues and lack of reporting. Therefore, a greater effort is needed to improve clinical research that supports evidence-based palliative care for patients with incurable cancer.

Twitter Marie Vinches @VinchesMarie and Sarah Kelly @1Sarah_M_Kelly

Contributors All authors have taken part in the planning and reporting of the work described in the article. TDR, LF, MT, SK, GR and MV conducted the data extraction. MV and AN conducted the data review and validation. All authors contributed to the manuscript, have reviewed and agreed upon the manuscript content. MV is responsible for the overall content as guarantor. 
Funding Marie Vinches, Laurene Fenwarth and Julien Peron's work as Fellows was supported by a grant from Fonds Cancer (FOCA), Teresa de Rojas, Mitsumi Terada and Giovanna Rossi's by a grant from the EORTC Cancer Research Fund (ECRF) and Sarah Kelly's by a grant from the European Society for Paediatric Oncology (SIOPE).

Competing interests None declared.

Patient consent for publication Not required.

Provenance and peer review Not commissioned; externally peer reviewed.

Data availability statement Data are available in a public, open access repository. https://clinicaltrials.gov/; ClinicalTrials.gov data are available to all requesters, both within and outside the United States, at no charge.

\section{ORCID iD}

Marie Vinches http://orcid.org/0000-0001-5147-2321

\section{REFERENCES}

1 WHO. Who definition of palliative care., 2012. Available: https://www.who.int/cancer/palliative/definition/en/ [Accessed 12 Aug 2019].

2 World Palliative Care Alliance. Global atlas of palliative care at the end of life, 2014. Available: http://www.who.int/cancer/ publications/palliative-care-atlas/en/

3 Kaasa S, Loge JH, Aapro M, et al. Integration of oncology and palliative care: a Lancet oncology Commission. Lancet Oncol 2018;19:e588-653.

4 Ferrell BR, Temel JS, Temin S, et al. Integration of palliative care into standard oncology care: American Society of clinical oncology clinical practice guideline update. J Clin Oncol 2017;35:96-112.

5 Temel JS, Greer JA, Muzikansky A, et al. Early palliative care for patients with metastatic Non-Small-Cell lung cancer. $N$ Engl J Med 2010;363:733-42.

6 Greer JA, Pirl WF, Jackson VA, et al. Effect of early palliative care on chemotherapy use and end-of-life care in patients with metastatic non-small-cell lung cancer. J Clin Oncol 2012;30:394-400.

7 Näppä U, Lindqvist O, Rasmussen BH, et al. Palliative chemotherapy during the last month of life. Ann Oncol 2011;22:2375-80.

8 Murtagh FEM, Bausewein C, Verne J, et al. How many people need palliative care? A study developing and comparing methods for population-based estimates. Palliat Med 2014;28:49-58.

9 Schrijvers D, Cherny NI. ESMO clinical practice guidelines on palliative care: advanced care planning. Ann Oncol 2014;25 Suppl 3:iii138-42.

10 García-Baquero Merino MT. Palliative care: taking the long view. Front Pharmacol 2018;9:1140.

11 Bouça-Machado R, Rosário M, Alarcão J, et al. Clinical trials in palliative care: a systematic review of their methodological characteristics and of the quality of their reporting. BMC Palliat Care 2017;16:10.

12 Kaasa S, Hjermstad MJ, Loge JH. Methodological and structural challenges in palliative care research: how have we fared in the last decades? Palliat Med 2006;20:727-34.

13 Khalil H, Ristevski E. The challenges of evidencebased palliative care research. Int J Evid Based Healthc 2018;16:136-7.

14 Abernethy AP, Capell WH, Aziz NM, et al. Ethical conduct of palliative care research: enhancing communication between Investigators and institutional review boards. J Pain Symptom Manage 2014;48:1211-21.

15 Higginson IJ. Research challenges in palliative and end of life care. BMJ Support Palliat Care 2016;6:2-4.
16 Aoun SM, Nekolaichuk C. Improving the evidence base in palliative care to inform practice and policy: thinking outside the box. J Pain Symptom Manage 2014;48:1222-35.

17 Ferris FD, Bruera E, Cherny N, et al. Palliative cancer care a decade later: accomplishments, the need, next steps -- from the American Society of clinical oncology. J Clin Oncol 2009;27:3052-8.

18 Ioannidis JPA, Fanelli D, Dunne DD, et al. Meta-research: evaluation and improvement of research methods and practices. PLoS Biol 2015;13:e1002264.

19 Ioannidis JPA. Meta-research: why research on research matters. PLoS Biol 2018;16:e2005468.

20 Liberati A, Altman DG, Tetzlaff J, et al. The PRISMA statement for reporting systematic reviews and meta-analyses of studies that evaluate health care interventions: explanation and elaboration. PLoS Med 2009;6:e1000100.

21 Home. Clinicaltrials.Gov. Available: https://clinicaltrials.gov/ ct2/home [Accessed 12 Aug 2019].

22 Groenvold M, Petersen MA, Aaronson NK, et al. The development of the EORTC QLQ-C15-PAL: a shortened questionnaire for cancer patients in palliative care. Eur J Cancer 2006;42:55-64.

23 Home - PubMed - NCBI. Available: https://www.ncbi.nlm.nih. gov/pubmed/

24 FDA. Food and drug administration amendments act (FDAAA) of 2007. Available: https://www.fda.gov/regulatoryinformation/selected-amendments-fdc-act/food-and-drugadministration-amendments-act-fdaaa-2007 [Accessed 12 Aug 2019].

25 Visser C, Hadley G, Wee B. Reality of evidencebased practice in palliative care. Cancer Biol Med 2015;12:193-200.

26 Bray F, Ferlay J, Soerjomataram I, et al. Global cancer statistics 2018: GLOBOCAN estimates of incidence and mortality worldwide for 36 cancers in 185 countries. CA Cancer J Clin 2018;68:394-424.

27 Universal health coverage (UHC). Available: https://www.who. int/news-room/fact-sheets/detail/universal-health-coverage-( uhc)

28 Wagstaff A, Neelsen S. A comprehensive assessment of universal health coverage in 111 countries: a retrospective observational study. Lancet Glob Health 2020;8:e39-49.

29 Oxford Centre for Evidence-based Medicine - Levels of Evidence (March 2009) - CEBM. Available: https://www.cebm. net/2009/06/oxford-centre-evidence-based-medicine-levelsevidence-march-2009/

30 Hui D, Parsons HA, Damani S, et al. Quantity, design, and scope of the palliative oncology literature. Oncologist 2011;16:694-703.

31 Seow H, Barbera L, Sutradhar R, et al. Trajectory of performance status and symptom scores for patients with cancer during the last six months of life. J Clin Oncol 2011;29:1151-8.

32 Teunissen SCCM, Wesker W, Kruitwagen C, et al. Symptom prevalence in patients with incurable cancer: a systematic review. J Pain Symptom Manage 2007;34:94-104.

33 Thomas JR, von Gunten CF. Clinical management of dyspnoea. Lancet Oncol 2002;3:223-8.

34 Hui D, Glitza I, Chisholm G, et al. Attrition rates, reasons, and predictive factors in supportive care and palliative oncology clinical trials. Cancer 2013;119:1098-105.

35 Carrieri D, Peccatori FA, Boniolo G. Supporting supportive care in cancer: the ethical importance of promoting a holistic conception of quality of life. Crit Rev Oncol Hematol 2018;131:90-5.

36 Van Beek K, Siouta N, Preston N, et al. To what degree is palliative care integrated in guidelines and pathways for adult cancer patients in Europe: a systematic literature review. BMC Palliat Care 2016;15:26. 
37 Mooney K, Berry DL, Whisenant M, et al. Improving cancer care through the patient experience: how to use patientreported outcomes in clinical practice. Am Soc Clin Oncol Educ Book 2017;37:695-704.

38 Europe I. Manifesto for a new approach for better medicine in Europe establishing treatment optimization as part of personalized medicine development. , 2019: 376, 710-3.

39 Kempf E, Bogaerts J, Lacombe D, et al. 'Mind the gap' between the development of therapeutic innovations and the clinical practice in oncology: a proposal of the European organisation for research and treatment of cancer (EORTC) to optimise cancer clinical research. Eur J Cancer 2017;86:143-9.

40 Sirgy MJ, Michalos AC, Ferriss AL, et al. The Qualityity-ofLife (QOL) research movement: past, present, and future. Soc Indic Res 2006; 76:343-466.

41 The world Health organization quality of life assessment (WHOQOL): position paper from the world Health organization. Soc Sci Med 1995;41:1403-9.
42 Staquet M, Berzon R, Osoba D, et al. Guidelines for reporting results of quality of life assessments in clinical trials. Qual Life Res 1996;5:496-502.

43 Ross JS, Mulvey GK, Hines EM, et al. Trial publication after registration in ClinicalTrials.gov: a cross-sectional analysis. PLoS Med 2009;6:e1000144.

44 Hudson KL, Collins FS. Sharing and reporting the results of clinical trials. JAMA 2015;313:355-6.

45 Tse T, Fain KM, Zarin DA. How to avoid common problems when using ClinicalTrials.gov in research: 10 issues to consider. BMJ 2018;361:k1452.

46 De Angelis C, Drazen JM, Frizelle FA, et al. Clinical trial registration: a statement from the International Committee of medical Journal editors. N Engl J Med 2004;351:1250-1.

47 Durham TA. How did these data get here? recommendations for the analysis of data from ClinicalTrials.gov. Ther Innov Regul Sci 2019;53:639-40. 